\title{
Hidden Donors: The Censoring Problem in U.S. Federal Campaign Finance Data
}

\author{
R. Michael Alvarez ${ }^{1} \quad$ Jonathan N. Katz ${ }^{1} \quad$ Seo-young Silvia Kim ${ }^{1}$
}

\section{Running Head: Hidden Donors}

keywords: campaign finance | small donors | 2016 election | data censoring | presidential campaigns

\footnotetext{
${ }^{1}$ California Institute of Technology. Kim is a Ph.D. candidate in the Division of Humanities and Social Science, Caltech, and is the corresponding author (sskim@caltech.edu); Alvarez is Professor of Political Science, Division of Humanities and Social Sciences, Caltech; Katz is the Kay Sugahara Professor of Social Sciences and Statistics, Division of Humanities and Social Sciences, Caltech. An earlier version of this paper was presented as a poster at the Polmeth 2017 and MPSA 2018 conferences; we thank participants for their comments and suggestions.
} 


\begin{abstract}
Inferences about individual campaign contributors are limited by how the Federal Election Commission (FEC) collects and reports data. Only transactions that exceed a cycle-to-date total of $\$ 200$ are individually disclosed, so that contribution histories of many donors are unobserved. We contrast visible donors and "hidden donors," i.e., small donors who are invisible due to censoring and routinely ignored in existing research. We use the Sanders presidential campaign in 2016, whose unique campaign structure received money only through an intermediary (or conduit) committee. These are governed by stricter disclosure statutes, allowing us to study donors who are normally hidden. For the Sanders campaign, there were seven hidden donors for every visible donor, and altogether, hidden donors were responsible for $33.8 \%$ of Sanders' campaign funds. We show that hidden donors start giving relatively later, with contributions concentrated around early primaries. We suggest that as presidential campaign strategies change towards wooing smaller donors, more research on what motivates them is necessary.
\end{abstract}

keywords: campaign finance | small donors | 2016 election | data censoring | presidential campaigns 
The United States has established one of the world's most comprehensive federal campaign disclosure processes. The Federal Election Commission (FEC), the federal entity which collects and disseminates these disclosures, produces data that are transparent, accessible, and up-to-date. Consequently, there has been an enormous amount of academic research on campaign finance, in particular on campaign expenditures, in the U.S. for the last few decades - see, for example, the recent review by Dawood (2015). Yet as we argue below, the FEC's data on campaign contributions is incomplete, and accordingly, our understanding of campaign contributions in the United States is incomplete as well.

One key feature of disclosure regulations in the U.S. is that currently, each federal campaign committee only has to report to the FEC contributions from individuals who have already given \$200 in aggregate to that campaign committee, either within a year or a two-year election cycle according to the committee type. The $\$ 200$ threshold has been in place for decades, and many donors' first few — in some cases all — contribution records are censored. ${ }^{1}$ We call this the censoring problem in campaign finance data, and the campaign contributors whose contribution amounts are below this threshold we call hidden donors.

Although a crucial part of the data generating process, the censoring problem and hidden donors have not been adequately addressed in the campaign finance literature (Key, 1964; Francia et al., 2003; Barber, 2016; Magleby, Goodliffe and Olsen, 2018). There is, after all, little that could be done about this censoring, short of changing the law. However, in aggregate, hidden donors are an important force that politicians must cater to when deciding ideological positions and campaign strategies. Hidden donors are likely to become more important for researchers to study in the near future, as more candidates are wooing individual donors, and positioning themselves as not "buyable" by corporate PAC money. ${ }^{2}$

Fortunately, we can get an estimate of the censoring problem due to the unique fundraising approach taken by the 2016 presidential campaign of Bernard "Bernie" Sanders. For the first time, we can observe all of a major presidential candidate's individual contribution records, without any of them being censored. This is because the Sanders campaign chose to receive money only through an intermediary committee, and so these contributions are known as "earmarked contributions." These transactions are governed by a different, stricter set of regulations, resulting in full disclosure. Through the Sanders presidential campaign, we can compare datasets in which the censoring problem is and is not present. While the "law of available data" has driven us to investigate visible donors almost exclusively, this paper, using the valuable opportunity presented by the 2016 Sanders campaign, studies the seldom-explored world of "hidden" donors.

We show that hidden donors differ substantially from the visible donors. We do this using only the administrative data from the FEC, where we statistically impute contributor race/ethnicity and gender using only the contributor's name and address, which augments the thin selection of covariates available just from campaign reports. We find that hidden donors are more likely to be female, non-white, and younger. They may also have different

\footnotetext{
${ }^{1}$ Prior to 1989, however, the data entry threshold of the Federal Election Commission was set at $\$ 500$. See the FEC's Thirty Year Report published in 2005. Also, because the $\$ 200$ restriction is with nominal dollars, the data have to be filtered using inflation adjustments.

${ }^{2}$ See Appendix D for additional information on the 2020 campaign and small donors.
} 
political goals or interests, as they are more likely to donate later in the election cycle than visible donors, as their contributions are concentrated at points in the election cycle when the race is contested. Most importantly, there were seven times more hidden donors than visible donors for Sanders - suggesting that past research focusing only on visible donors may have only observed the tip of the iceberg in terms of individual donor behavior. We suggest that as presidential campaign fundraising methods are now shifting towards an individual and small-donor paradigm, more analysis of small donor behavior is necessary.

\section{Past Research}

Given the limitations of the FEC's campaign contributions data, most papers that study individual campaign contributors use survey data (Brown, Powell and Wilcox, 1995; Francia et al., 2003; Barber, Canes-Wrone and Thrower, 2017; Rhodes, Schaffner and La Raja, 2018). However, such studies inevitably rely on the FEC records to sample respondents, meaning that they are restricted to visible donors. The comparisons that studies often make are between visible contributors and average citizens, or between different types of visible contributors. These studies have not examined how hidden contributors differ from those who are visible, nor do they compare hidden contributors and non-contributors.

It is not that scholars are altogether unaware of this censoring problem. Key (1964) noted that scholars do not know much about "little givers." Francia et al. (2003) recognized the threshold by labeling donations after the $\$ 200$ threshold as "significant" donations, while Heerwig (2016) called these donors "elite" donors. Barber (2016), while discussing how his survey does not include donors who gave less than $\$ 200$ in a footnote, said that his picture of individual donors' motivations may be incomplete, if unitemized (hidden) donors have different motivations from those who are itemized (visible).

Although this censoring problem is well-known, there is no remedy short of changing federal campaign finance law, or asking campaigns to voluntarily report every small donation. Unfortunately, as contributing money to electoral campaigns is not a widespread form of political participation, the relative rarity of campaign donors in the population of adult Americans means that it is difficult to draw a representative sample of donors overall, and small or hidden donors specifically. There have been a few studies using the American National Election Studies (ANES) surveys (Panagopoulos and Bergan, 2006; Johnson, 2013), but the sample size that report contributing is very small-for instance, in the 2008 election, only $9.9 \%$ of respondents reported to have contributed money to a specific candidate. ${ }^{3}$

Despite these limitations, the literature has worked to generate stylized facts about the small, hidden donors. Most obviously, past research has argued that the hidden donors have less income than visible donors, because giving is related to disposable income. For example, Verba, Schlozman and Brady (1995) show that the percentage of family income contributed to political campaigns increases with household income, sharply rising at $\$ 50,000$

\footnotetext{
${ }^{3} 2008$ Time Series Study, ANES, May 19, 2015 version, sub-sample of post-election survey respondents: question V085033.
} 
or more (See also Wilcox (2008) and Malbin (2013)). A series of papers such as Graf, Malbin and Panagopoulos (2006), Panagopoulos and Bergan (2007), and Malbin (2009) exploit surveys based on donor lists from the public matching funds program, in which presidential candidates can apply for government funding up to the first $\$ 250$ of each contribution, but only after full disclosure. Johnson (2010) and Culberson, McDonald and Robbins (2018) tackle the problem by using aggregate amounts reported at the campaign level, concluding that small donors are linked to more ideologically extreme candidates, although there is some mixed evidence with this argument (Malbin, 2013).

The most recent work that has systematically compared visible and hidden campaign contributors is Magleby, Goodliffe and Olsen (2018). They were able to cooperate with major presidential candidates in 2008 and 2012 to receive a random sample of contributors who gave donations of all sizes. They generally do not find important ideological differences between visible and hidden donors. ${ }^{4}$ In terms of their demographic profiles, they found that visible donors are older and wealthier than hidden donors. Hidden donors, meanwhile, were more likely to have been solicited to contribute online. Magleby, Goodliffe and Olsen (2018) makes it clear that campaigns prioritize large donors over the small, especially due to changes introduced by the Bipartisan Campaign Reform Act of 2002. However, appeals to small donors are becoming more prevalent in American campaigns, especially in recent elections as the Internet is becoming central to campaign fundraising (Malbin, 2013; Karpf, 2013). In that case, it is crucial to study who these small donors are, and what their donation strategies may be, so that we can understand how they influence campaign strategy.

This paper contributes to the literature on small donors by analyzing an entire donor population for a presidential candidate using complete individual-level data. While our data do not have the more in-depth questions and breadth that are available in surveys like that of Magleby, Goodliffe and Olsen (2018) or Graf, Malbin and Panagopoulos (2006), we are not limited to survey respondents - we can bring the entire population of visible and hidden Sanders contributors to study, which can complement the mostly survey-based existing literature. This allows us to provide a set of analyses regarding the hidden donors in 2016, to document their contribution behavior, and to establish a baseline for future research on small and hidden donors.

\section{The Censoring Problem in Campaign Finance Data}

In this Section, we discuss the censoring problem that is the consequence of federal regulations on individual campaign contributions - how the censoring problem may manifest itself, and how we can use the data from the 2016 Sanders campaign to estimate the extent of campaign contribution censoring.

\footnotetext{
${ }^{4}$ They refer to this comparison as itemized vs. small donors.
} 


\section{Code of Federal Regulations, Title 11}

The Federal Election Commission administers federal campaign finance law, under Title 11 of the Code of Federal Regulations. A federal campaign committee that meets the conditions will be registered with the FEC and will regularly file reports that disclose funds that are raised and spent. 11 CFR 104.3 Contents of Reports dictates this, and how the information on receipts are censored is stated in 11 CFR 104.3(4)(i): ${ }^{5}$

(4)(i) Each person, other than any political committee, who makes a contribution to the reporting political committee during the reporting period, whose contribution or contributions aggregate in excess of $\$ 200$ per calendar year (or per election cycle in the case of an authorized committee), together with the date of receipt and amount of any such contributions, except that the reporting political committee may elect to report such information for contributors of lesser amount(s) on a separate schedule;

When a contribution pushes the sum of aggregated contributions over this threshold, this contribution is "itemized." Unitemized contributions are aggregated into a lump-sum and reported as a single number, and hence no other details are reported for unitemized contributions. Also, donors who do not meet the threshold are entirely absent from receipt reports that campaigns file with the FEC.

As aforementioned, we utilize intermediary committees to investigate the censoring effect on the data. 11 CFR 110.6 Earmarked Contributions provide details as to what intermediary committees are, and what they should disclose. While earmarked contributions are money designated to a clearly identified candidate/committee, intermediary committees (also called conduits) are "anyone who receives and forwards an earmarked contribution to a candidate or candidate's authorized committee."6 The following excerpt from the FEC summarizes the special disclosure requirements:

A political committee that serves as a conduit of an earmarked contribution must disclose the earmarked contribution, regardless of amount, on two separate reports: the committee's next regularly scheduled FEC report, and a special transmittal report sent to the recipient authorized committee. 110.6(c)(1).

As we can see, intermediary committees have stricter disclosure requirements than other campaign committees. They must report all transactions, not just those that cross the $\$ 200$ threshold - see Appendix A for details. The issue, which we explain with detailed hypothetical examples in Appendix B, is that for campaigns that undergo the typical process, we will not observe campaign contributors who donate less than $\$ 200$.

\footnotetext{
${ }^{5}$ We immediately see that aside from the arbitrary $\$ 200$, there are two additional problems: one is that the $\$ 200$ is in nominal dollars, unadjusted for inflation, and the other is that whether a campaign committee is authorized or not - which is, in the campaign finance jargon, another name for candidateaffiliated committee, especially the principal campaign committees. For an exact definition, see 11 CFR 9032.1. We largely avoid the first problem as we only use a single cycle's observation, and we will for the moment ignore the second problem.

${ }^{6}$ While conduit or intermediary committees are interchangeably used and the FEC seems to prefer the former, we use the terminology 'intermediary committees.'
} 


\section{The 2016 Sanders Campaign}

The 2016 Sanders campaign was unique in many ways, including their approach to campaign finance. In 2016, one of the important issues for Sanders was his campaign's stance against the influence of "big" money and special interests. He claimed early on that his campaign would not be allied with any super PACs (Lee, 2016; Qiu, 2015). In addition, the Sanders campaign was reported by the media in late 2015 to have organized only seven traditional fundraisers, while the Clinton campaign had by then organized more than 110 (Associated Press, 2015). In March 2016 it was further reported that the campaign had only two more traditional fundraisers (Gaudiano, 2016).

This distaste for conventional fundraising meant that most of Sanders' donations were digitally processed. His website noted on April 30, 2016 that $94 \%$ of its contributions were made online. ${ }^{7,8}$ His fundraising appeals were mostly digital, using emails, texts, and social media (Corasaniti, 2016), and his website pointed to the ActBlue contributing page. The campaign used no other online platforms and had no offline fundraising staff. Hence, almost all individual donors who desired to contribute to Sanders would have had to donate through ActBlue, regardless of their wealth, connections, or intentions.

Because ActBlue is an intermediary committee, we can track all Sanders donors, regardless of the size of their donations to his campaign, which as far as we know is a first for federal campaigns. Regardless of whether they gave fifty cents or maxed out individual contribution limits, they would be captured in ActBlue reports. This means that the censoring problem disappears with respect to Sanders' contributors, giving us an unprecedented opportunity to study both visible and hidden donors to a major presidential campaign. See Appendix C for details.

It is true that the data are restricted to a subset of presidential donors, and that Sanders is an unusual candidate, as he is a very progressive Independent and the first presidential candidate to rely exclusively on individual contributions, mostly raised online. ${ }^{9}$ However,

\footnotetext{
${ }^{7}$ The website address is https://berniesanders.com/revolution/. Our final estimate of how much Sanders campaign received online is $98.1 \%$ of his total individual contributions, which is greater than the $94 \%$ reported in the website. The discrepancy seems to arise because the campaign's estimate was calculated before mid-May 2016 - and we believe that many of the donations made after that point in the campaign were made online. That the $94 \%$ is calculated before mid-May can be inferred from the Wayback Machine's snapshot of the website, the first snapshot of which is at May 21, 2016, and shows the $94 \%$ claim.

${ }^{8} 5.1 \%$ of donors' year-to-date contribution records do not match the actual sum of records, (1) potentially because they have not been sufficiently record linked due to the conservative linking of contribution records that constitute the same individual, (2) the committee inaccurately calculated the contributor year-todate by mixing up different contributors, or (3) because these donors have given in the few traditional fundraisers we discussed earlier. The third possibility seems viable, since we find that $68.7 \%$ of those with record irregularities are visible. The second explanation may also have merit, because we often find that intermediate records of contribution year-to-date sums are grossly inaccurate. This speaks to the difficulty of working with campaign finance data.

${ }^{9}$ As discussed earlier, there is some debate and mixed evidence in the literature about whether small donors are polarizing - that is, whether ideologically extreme candidates attract more small donors (Wilcox, 2008; Bonica, 2011; Malbin, 2013; Johnson, 2010; Culberson, McDonald and Robbins, 2018; Magleby, Goodliffe and Olsen, 2018). Unfortunately, although this is a very important and interesting question, due to the nature of our data, we cannot test this claim in this paper.
} 
there are unmistakable advantages in utilizing the Sanders data. We may never have another major candidate whose contributions are so transparently presented to the public, and whose donors are exposed, both small and large. ${ }^{10}$ This is also the first step into understanding the unique data generating process presented by intermediary committees.

Table 1: Proportion of Unitemized Contributions in Individual Contributions, Dollar Amounts, 2016 Election

\begin{tabular}{lr}
\hline Office/Party & $\begin{array}{c}\text { Unitemized Individual \$/ } \\
\text { (Unitemized \$ + Itemized \$) }(\%)\end{array}$ \\
\hline House Democrats & 22.4 \\
House Republicans & 13.9 \\
Senate Democrats & 25.0 \\
Senate Republicans & 18.7 \\
\hline Hillary Clinton (Dem.) & 25.8 \\
Bernie Sanders (Dem.) & 58.1 \\
Donald Trump (Rep.) & 64.9 \\
Ted Cruz (Rep.) & 38.5 \\
\hline
\end{tabular}

Table 1 shows the proportion of unitemized contribution amounts relative to all individual contributions for the four major presidential candidates of 2016, as well as House and Senate Democrats and Republicans in 2016. We see in Table 1 that $58.1 \%$ of Sanders' contribution amounts were unitemized, and a large proportion of contribution amounts going to Trump, Clinton, and Cruz were also unitemized. The same is the case for House and Senate campaigns in 2016. Note that the total number of unitemized contributions is not the same as the sum of funds contributed by hidden donors, since the first $\$ 200$ of visible donors are still labeled as unitemized, and not corrected in retrospect. Again, this demonstrates that there are many hidden donors, and that they play a substantial role in elections, especially in presidential races.

\section{Data}

The data we use were obtained from the Federal Election Commission. One can use the FEC "Download Bulk Data" page (https://www.fec.gov/data/browse-data/?tab=bulk-data) to download the individual contributions data or or build a database using the the OpenFEC API (https://api.open.fec.gov/developers/). While the bulk data are easy to download and do not need deduplication, they contain only visible donors meeting the $\$ 200$ threshold, and they also lack the donor's address. Hence we built our database using raw FEC data using the OpenFEC API, and downloaded all of the 2016 cycle's raw individual

\footnotetext{
${ }^{10}$ While the 2020 Democratic primary contenders are also shunning corporate PACs, their fundraising also incorporates the traditional individual fundraising, such as private, invited events.
} 
contribution data. ${ }^{11}$

We then augmented the records with geographic identifiers such as congressional district information after geocoding each record. ${ }^{12}$ We also used record linkage to connect the donations that came from the same individual contributor. We use exact matching on first name, last name, and street address, and allow matches if there is variation in these variables but the employer and occupation is exactly the same for consecutive contribution records. We use exact matching to take advantage of the sequential nature of repeating contributions - if donor $A$ has been a teacher for the first part of 2016, and has a different address starting mid2016, we would still link her records together given that the names and occupation/employer stay consistent. To prevent false matches, we only match within the state.

Next, we focused specifically on contributions to Bernie 2016, the Sanders presidential committee, and to ActBlue, creating a union of contribution records to Sanders while filtering out duplicate contributions. This is a very important and time consuming step, because there is always a separate receipt for donor giving to the intermediary committee, the intermediary committee giving to the final destination campaign, and the acknowledgement of a donor giving to the final destination campaign. The OpenFEC API recognizes this and offers guidance as to how to exclude some entries as duplicates in its Receipts description. Every intermediary contribution must be checked against the destination committee's reports to eliminate duplicate entries, which will have the same contribution amount, date, and personal details. This way, we can uncover donations ranging from a dollar to the $\$ 2,700$ individual limit. The campaign reports do not contain gender or racial/ethnic information per se, and only carry name, address, the money's destination, date, occupation, and employer, the minimal requirements by the federal regulations.

Finally, we supplemented the contributions data, using names and geo-locations to infer gender and race/ethnicity. To infer gender for each individual contributor, we use the $\mathrm{R}$ package gender (Mullen, 2018; Blevins and Mullen, 2015) of rOpenSci project, which uses first names and the Social Security Administration's yearly dataset of first names to infer the gender of the donor. If the donor has voluntarily entered a prefix such as a Mr., we override the gender inference with the gender inferred from the self-reported prefix. For race/ethnicity, we use the $R$ package wru (Khanna, Imai and Jin, 2017; Imai and Khanna, 2016). That is, we utilize the Census Bureau's surname list and Bayes' rule to infer the race. In particular, we use a Census block level inference, after geocoding each address using the Census Geocoder and obtaining the latitude and longitude of the address. The Census block being the smallest unit in which detailed surname distributions are provided by the 2010 Census, this enables the most accurate approximation of race. For the empirical validation of the method, see Imai and Khanna (2016).

\footnotetext{
${ }^{11}$ The $\mathrm{R}$ scripts used to build the database will be publicly available upon publication. This script downloads the data as text files in batches of 100 records, resulting in more than 1,133,000 files and over 100 million records of individual transactions.

${ }^{12}$ Given that each record had a limited number of fields, this database has a single table, and can be linked to other tables in future research (by contributor name and address, for example).
} 


\section{Who Are the Hidden Donors?}

We define a Sanders contributor as anyone who donated to Sanders' presidential campaign committee during the 2016 presidential election cycle. The committee launched on April 30, 2015 and the cycle ended on December 31, 2016. ${ }^{13}$ The total estimated number of Sanders contributors is over 2 million, including both visible and hidden donors, a large base of donors. However, among them, only $12.4 \%(250,352$ out of 2,017,638) would have been visible if the Sanders campaign did not receive individual contributions only through intermediary committees. In other words, there were seven times more contributors when hidden donors were included. This simple fact shows the potential magnitude of the censoring problem, and is similar to the numbers reported in Magleby, Goodliffe and Olsen (2018), where they estimated that $82 \%$ of Romney donors and $88 \%$ of Obama donors in 2012 were small donors. ${ }^{14}$

Figure 1 shows the donor base compared to the population estimated by the 2016 American Community Survey, geographically. Not surprisingly, we can see that the Sanders' donor population is large in Vermont, with the town of Newfane with the largest proportion of Sanders donors (32\% of residents). $74 \%$ of the top 100 Zip Codes in Sanders-donor population relative to their total population are in Vermont, with California and Massachusetts trailing respectively at $12 \%$ and $5 \%$.

Table 2 describes the demographic difference between visible and hidden Sanders contributors. A hidden donor is more likely to be female and a racial or ethnic minority, whether black, Hispanic, or Asian. Note that the differences in gender are consistent with previous literature (Graf, Malbin and Panagopoulos, 2006; Magleby, Goodliffe and Olsen, 2018).

While the percentages of black or Asian contributors do not differ greatly between visible and hidden Sanders donors, a hidden contributor is much more likely to be Hispanic than a visible one. ${ }^{15}$ This is an interesting observation, and could reflect the fact that the Hispanic electorate is generally younger than other racial/ethnic groups (Patten, 2016), and perhaps unable to afford donating more than $\$ 200$.

Table 2 also shows the top 10 types of employment of all 2016 contributors and their percentage for the subset of Sanders supporters. Noticeable is the presence of students in the hidden donor population, while the likelihood of being retired is much higher for visible donors. This signals a difference in age groups, i.e., that the hidden donors are likely to be younger in age. In addition, while visible donors are more likely to report being attorneys and physicians, hidden donors are slightly more likely to be teachers. Considering that the

\footnotetext{
${ }^{13}$ Statement of Organization, Bernie 2016. Available at http://docquery.fec.gov/pdf/537/ 15031422537/15031422537.pdf, last accessed November 19, 2018.

${ }^{14}$ One thing that should be noted is that both Obama and Romney were candidates that won the primaries, while Sanders did not make it to the general election. Had he won the primaries, these descriptives may have changed. See Appendix F for a brief illustration.

${ }^{15}$ All differences are statistically significant. We do not offer p- or t-statistics separately for any of our descriptive statistics - because the sample size is so large, every difference that we present in this paper is statistically significant $(p<0.001)$.
} 


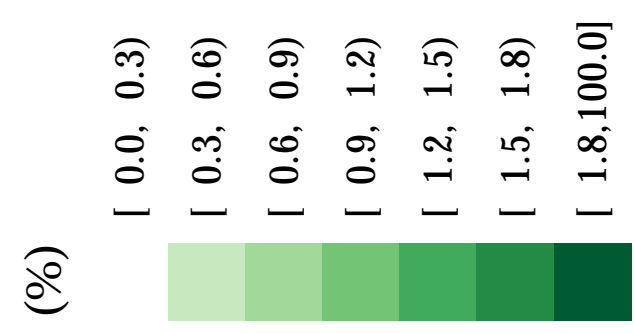

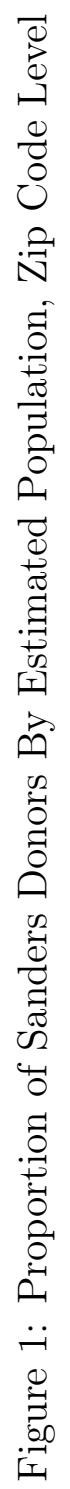

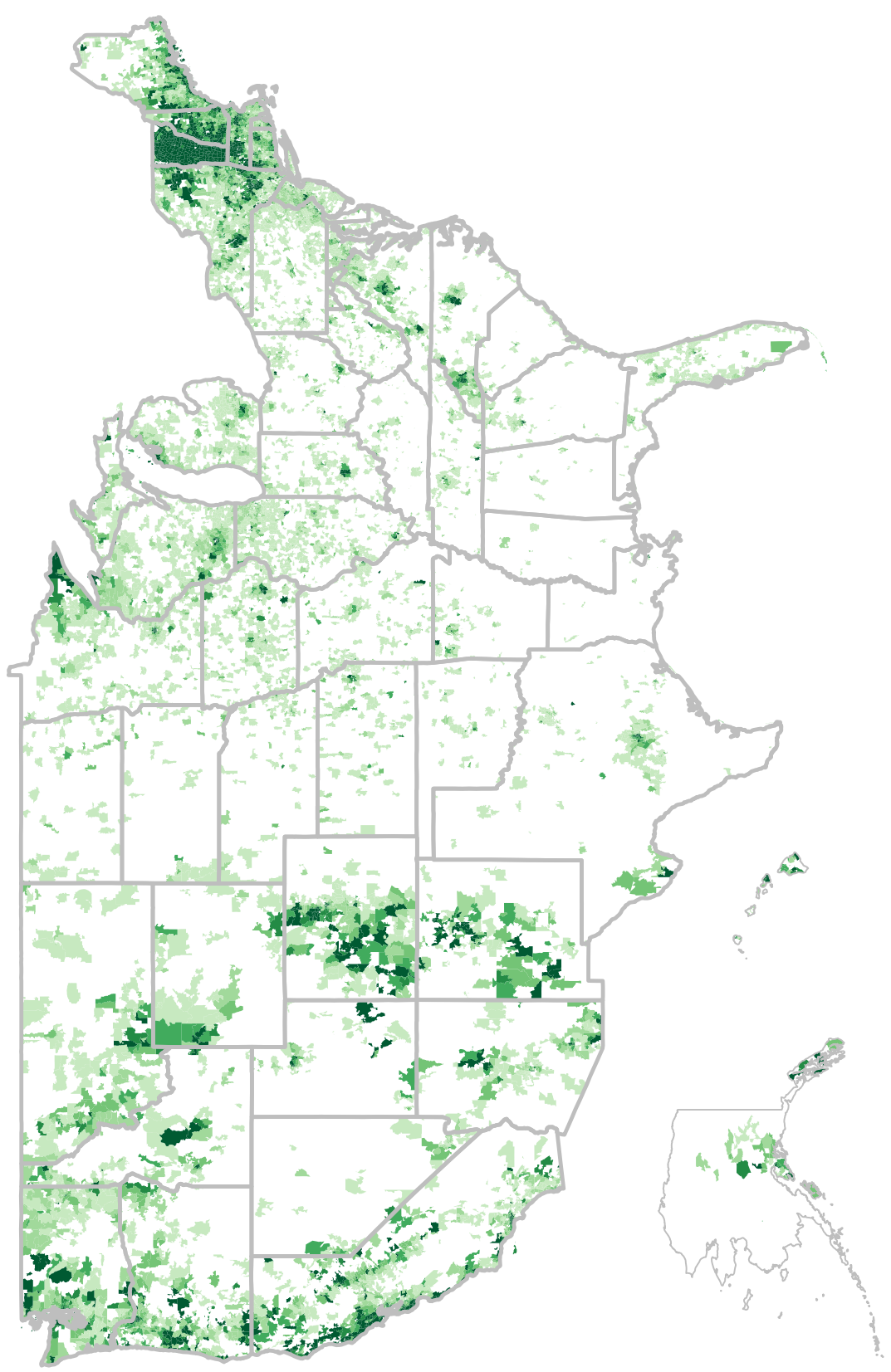


Table 2: Demographics and Occupations of Visible and Hidden Contributors, 2016 Sanders Campaign

\begin{tabular}{lrr}
\hline & Visible & Hidden \\
\hline \% of Men & $57.2 \%$ & $53.2 \%$ \\
\hline \% of Whites & $90.5 \%$ & $86.7 \%$ \\
\% of Blacks & $2.8 \%$ & $3.0 \%$ \\
\% of Hispanics & $4.2 \%$ & $7.4 \%$ \\
$\%$ of Asians & $2.5 \%$ & $2.9 \%$ \\
\hline \% of Unemployed & $26.7 \%$ & $25.7 \%$ \\
\% of Engineers & $4.8 \%$ & $3.1 \%$ \\
$\%$ of Teachers & $4.1 \%$ & $4.9 \%$ \\
$\%$ of Retired & $3.9 \%$ & $1.3 \%$ \\
$\%$ of Attorneys & $2.3 \%$ & $1.1 \%$ \\
\% of Professors & $2.1 \%$ & $1.2 \%$ \\
\% of Physicians & $2.1 \%$ & $0.8 \%$ \\
$\%$ of Consultants & $1.9 \%$ & $1.3 \%$ \\
$\%$ of Students & $1.2 \%$ & $4.0 \%$ \\
$\%$ of Homemakers & $0.4 \%$ & $0.3 \%$ \\
\hline
\end{tabular}

(Occupations are sorted by the visible donor percentage for a better contrast.)

average annual salary of teachers in public schools was $\$ 56,383$ in $2012^{16}$ while a physician's lowest pay was $\$ 189,000^{17}$, this hints that income and wealth might explain why some donors are hidden while others are not, which is as expected. However, it is also interesting to note that the proportion of visible donors reporting unemployment is slightly higher.

\section{Differences in Contribution Patterns}

Given the demographics differences that we have documented earlier, here we investigate whether hidden and visible donors vary in the amount, frequency, and timing of their donations.

\section{Amount and Number}

Table 3 displays the basic descriptive statistics for Sanders contributions in the 2016 cycle. Here we see the important differences between visible and hidden contributors. Figure 2 shows the density plot of the sum of Sanders contributions, capped at $\$ 500$ to clearly highlight the difference. We see that the distribution of the contribution sum is extreme valued, much

\footnotetext{
${ }^{16}$ National Center for Education Statistics, Digest of Education Statistics: 2013

${ }^{17}$ Forbes, The Best- And Worst-Paying Jobs For Doctors, July 20, 2012.
} 
more pronounced with the hidden donors' data. Also, the distribution of hidden donors' contributions exhibits peaks at various salient contribution amounts such as $\$ 10(12.0 \%$ of hidden donors), $\$ 15$ (8.5\%), $\$ 50$ (7.6\%), and $\$ 27(6.1 \%)$. There are no such extreme peaks for visible donors' sum of contributions. The mode for visible donors is $\$ 250(4.8 \%)$, followed by $\$ 300(3.1 \%)$.

Table 3: Sanders Contributions, Visible and Hidden Contributors, 2016 Sanders Campaign

\begin{tabular}{lrr}
\hline & Visible $(12.4 \%)$ & Hidden $(87.6 \%)$ \\
\hline \hline Sum of contributions: & $\$ 632.0$ & $\$ 45.7$ \\
\hline Mean & $\$ 270.0$ & $\$ 15.0$ \\
\hline Q1 & $\$ 400.0$ & $\$ 27.0$ \\
\hline Q2 & $\$ 700.0$ & $\$ 60.0$ \\
Number of contributions: & 13.2 & 2.5 \\
\hline Mean & 5 & 1 \\
Q1 & 10 & 1 \\
\hline Q2 & 17 & 3 \\
\hline \hline Median first contribution date & $10 / 04 / 2015$ & $01 / 29 / 2016$ \\
Median last contribution date & $05 / 18 / 2016$ & $03 / 09 / 2016$ \\
\hline of donors who gave to Sanders, after & & $44.9 \%$ \\
Super Tuesday & $83.5 \%$ & $16.9 \%$ \\
Acela primaries (Super Tuesday III) & $63.3 \%$ & $4.6 \%$ \\
Clinton became presumptive nominee & $29.5 \%$ & $0.8 \%$ \\
Sanders endorsed Clinton & $5.5 \%$ & $0.0 \%$ \\
\hline
\end{tabular}

The $\$ 27$ contribution amount is particularly interesting. This is an amount that the Sanders campaign deliberately made salient mid-election, emphasizing that the average donation size to the campaign was $\$ 27$, and thus the campaign relied on small donors and not on the fat-cats of Wall Street. ${ }^{18}$ This emphasis has been frequently covered by the media (Bump, 2016; Foran, 2016; Mehta et al., 2016), and was further echoed in Sanders's later campaign strategies, as they added a $\$ 27$ donation option in their suggested contribution amounts. And indeed the campaign had successfully mobilized small donors enough that its median donor was a one-time giver of $\$ 27$. However, $\$ 27$-giving is more indicative of a visible donor compared to the benchmark distribution. While $20 \%$ of Sanders donors have given $\$ 27$ at least once, conditional on a $\$ 27$ giving record, a donor is $26.5 \%$ likely to be visible. This may suggest that such compliance with the campaign message - enough to choose such a non-salient amount - is indicative of donor loyalty, who ends up contributing enough to earn the visibility.

\footnotetext{
${ }^{18}$ Note that the individual contribution limit of 2016 was $\$ 2,700$, which could have resulted in this value.
} 
Figure 2: Distribution of Contribution Sum to Sanders, Visible and Hidden Contributors, Truncated at $\$ 500$

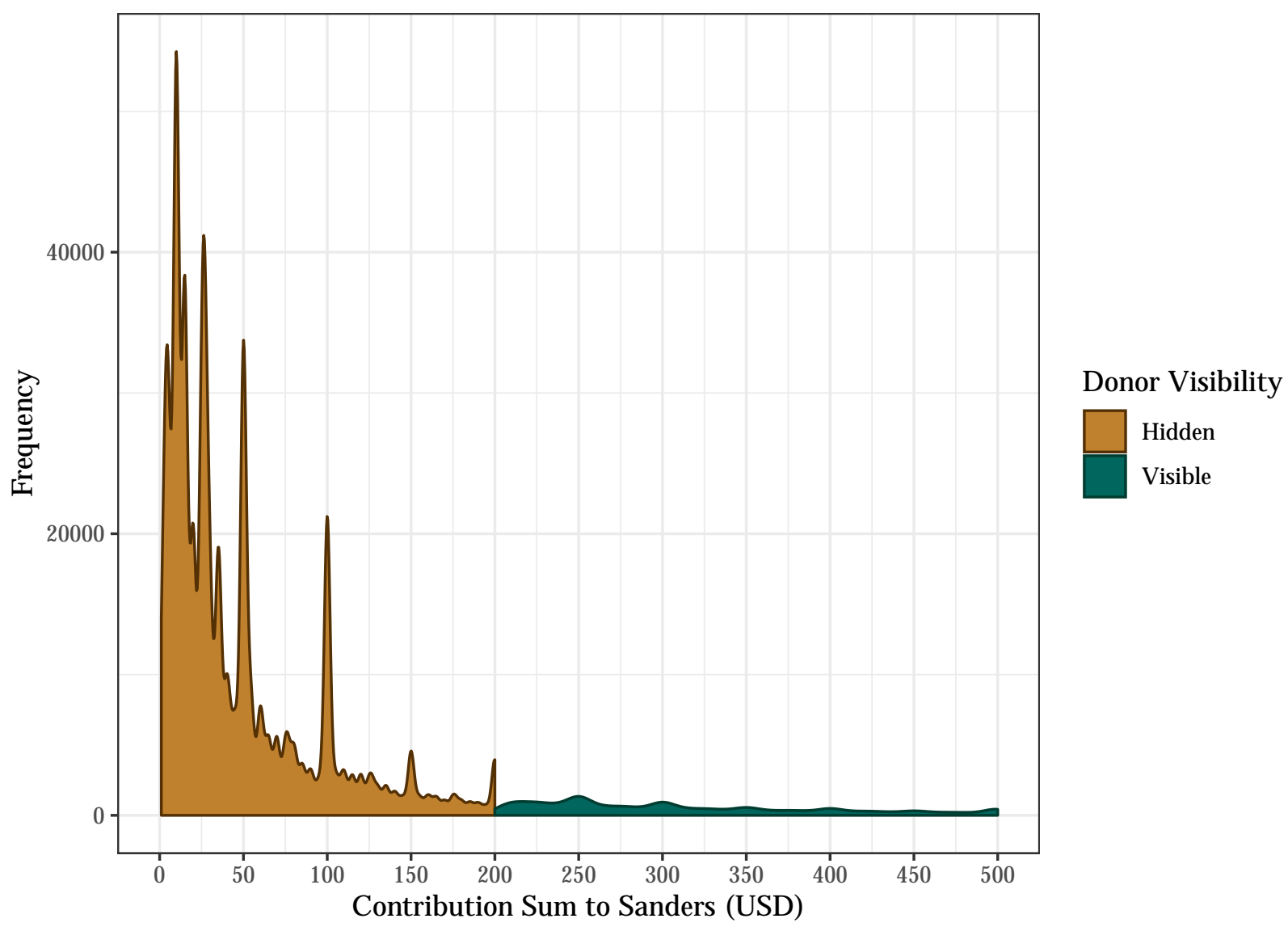

Aside from the obvious differences in contribution amounts, Table 3 also shows important differences by the number of contributions. Note that visible donors have given multiple times - indeed, while the median hidden donor has given only once, the median visible donor has given ten times to Sanders. This shows that not all visible donors are one-time donors of hundreds of dollars.

\section{Timing}

The timing of campaign contributions has not been widely analyzed, though there are a few recent papers on the subject (Christenson and Smidt, 2011; Smidt and Christenson, 2012; Mitchell et al., 2015; Magleby, Goodliffe and Olsen, 2018). These studies aggregate the number of donations on a daily level to study donation dynamics. Magleby, Goodliffe and Olsen (2018) aggregated the data separately for small and large donors, and concluded that the same events motivate large and small donors alike, and thus they seem to be driven by the same dynamics. 
However, the timing of giving disaggregated by first and last date of contributions may provide additional insight into donor motivations. If we view contributing to campaigns as a rational act in which a donor weighs her marginal benefits and costs, whether her gift is expressively or instrumentally motivated, the first contribution date reveals when the marginal benefits first exceed marginal costs of the person. If donations are driven by solicitation, timing may show how an equilibrium is struck between demand and supply.

Table 3 also shows various summaries of when the donors choose to give. Notice that visible contributors on average enter earlier in the race with their first contribution. While visible donors give long before the primaries, hidden donors enter right before the primaries start. Visible donors also leave later than hidden contributors, again by a difference of two to three months, a substantial amount of time. Note how half of the hidden donors started to leave after March 9th, although that was the day after the Sanders' surprise win in Michigan. In fact, by April 26 (the time of the so-called Acela primaries), less than one in six Sanders hidden donors remained (16.9\%). For visible donors, a majority of them stopped only after May 18.

Table 3 shows the percentage of donors who gave to Sanders or other committees after some key dates in which Sanders' prospect declined. We include Super Tuesday (March 15), the Acela primaries (April 26), when Clinton became a presumptive nominee (June 6), when Sanders officially endorsed Clinton (July 12th), and when the Democratic Convention officially closed (July 28). Note that the percentage of hidden donors who give to Sanders rapidly declines as the election progresses. This contrasts with visible donors. By the time that Clinton is the presumptive nominee, almost $30 \%$ of visible donors still opened their wallets for further campaign contributions to Sanders, while only $5 \%$ of hidden donors did. ${ }^{19}$ This suggests that "hidden" status was achieved because they were not attracted to give until the race was contested, and they were also quicker to lose interest. That hidden donors are late entrants to the market signals that they may not have been strong supporters to begin with, and that they may have been persuaded to give only after Sanders gained sufficient momentum. ${ }^{20}$ Indeed, it is surprising to see that so many visible donors contributed to Sanders after he had effectively lost his quest for the Democratic nomination. Even if we account for the possibility of campaigns mislabeling donations with different dates then they actually received, the percentage seems substantial.

The difference in enthusiasm could be attributed to many factors, such as ideological differences (Ensley, 2009), candidate valence, information costs, or contributor's budgets. For example, given that donors are instrumental, the ones who are further away from Sanders ideologically may have been attracted to give by his rising prospects, but as his viability fell, they withdrew as their marginal benefit of giving fell below the costs. It could be that these are donors who are generally not sufficiently interested in politics to consider giving,

\footnotetext{
${ }^{19}$ Overall, $22.2 \%$ of donors started to give before the Iowa Caucuses but also stopped before the Iowa Caucuses, while $35.2 \%$ of donors gave before and after the Iowa Caucuses. Similarly, $35.9 \%$ started to give before Super Tuesday but not after, while $39.1 \%$ of donors gave before and after Super Tuesday.

${ }^{20}$ Note that this difference in timing is best highlighted also because Sanders had a lengthy campaign, as he did not leave the race until the Democratic convention. If a less viable candidate had dropped out earlier or his/her prospects dwindled much more quickly, while the difference will still hold, it would be more subtle.
} 
and only when Sanders became a serious figure, were attracted just enough to give once or twice. There could be a donor class with limited budget for political donations, for instance due to a lower family income, who thus cannot afford to give expressive donations such as those made after Sanders loses the primary race. With only administrative data we cannot immediately conclude whether either of these two explanations hold true, but this is worthy of further investigation.

\section{Differentiating Visible Donors}

Given the results above, there is a strong possibility that visible donors become visible simply because they have patiently given many times, and eventually gave more than the $\$ 200$ threshold. These donors, who we call eventually visible donors, may be different from the ones who have given over $\$ 200$ in their first contribution, who we will call immediately visible donors. If for instance a donor gives $\$ 50$ monthly starting January 2016 and opts out during or before April, she will be hidden, while if she remains to give once more until May, she becomes visible. Distinguishing the different types of visible donors may be important in understanding differences in their political behavior from hidden donors.

Table 4 replicates Table 3 with these classifications. The immediately visible donors constitute only $2.7 \%$ of the donor population, while the eventually visible donors are $9.7 \%$ of the donor population. Note that the number and sum of contributions are correlated, as there is a $\$ 2,700$ cap on the maximum amount of individual contributions - a donor who gives $\$ 500$ regularly cannot give more than 5 times. Altogether, the immediately visible donors $(2.7 \%$ of donors) give $20 \%$ of the individual contributions amount, the eventually visible donors $(9.7 \%)$ give $46.2 \%$, and the hidden donors $(87.6 \%)$ give $33.8 \%$. Again, this now excludes the first $\$ 200$ from visible donors, and hence the proportion is reduced from what is presented in Table 1. Each class is a formidable force in the financial electorate, but it is the eventually visible donors who filled the campaign chest of the presidential candidate. Table 2's equivalent with these classifications is available in Appendix E.

On average, the eventually visible donors start early, but give frequently and are late to leave the donation game. For other campaigns than the Sanders campaign, we would not have been able to observe their first few donations, and hence would not know exactly when they entered. Instead, we would have observed only the date that they crossed the $\$ 200$ threshold and became visible, the median of which is March 3, 2016, and would have only known that they would have entered before that. Because the best predictor of giving is their past giving history, it makes sense for campaigns to target early givers and attempt to

solicit more money from them, given that they have not maxed out. It appears that donors who become eventually visible are the most loyal - or persuadable - set of donors. Indeed, conditional on having first given before June 1, 2015, i.e., within two months of launching the campaign, $27.6 \%$ will become eventually visible.

One interesting point is that the median date of first donation for hidden donors and for immediately visible donors is similar - only four days apart, a week to go before the Iowa caucuses. The first and third quartiles are also similar: respectively September 12, 2015 vs. 
Table 4: Sanders Contributions, Immediately Visible, Eventually Visible, and Hidden Donors, 2016 Sanders Campaign

\begin{tabular}{lrrr}
\hline & $\begin{array}{c}\text { Immediately } \\
\text { Visible }(2.7 \%)\end{array}$ & $\begin{array}{c}\text { Eventually } \\
\text { Visible }(9.7 \%)\end{array}$ & $\begin{array}{r}\text { Hidden } \\
(87.6 \%)\end{array}$ \\
\hline \hline Sum of contributions: & & & \\
Mean & $\$ 876.0$ & $\$ 564.0$ & $\$ 45.7$ \\
Q1 & $\$ 277.0$ & $\$ 269.0$ & $\$ 15.0$ \\
Q2 & $\$ 500.0$ & $\$ 389.0$ & $\$ 27.0$ \\
Q3 & $\$ 1,000.0$ & $\$ 638.0$ & $\$ 60.0$ \\
Number of contributions: & & & \\
Mean & 1 & 7.2 & 2.5 \\
Q1 & 3 & 11 & 1 \\
Q2 & 7 & 19 & 3 \\
\hline Q3 & $01 / 25 / 2016$ & $09 / 23 / 2015$ & $01 / 29 / 2016$ \\
\hline \hline Median first contribution date & $01 / 25 / 2016$ & $03 / 04 / 2016$ & - \\
Median date when voter became visible & $04 / 03 / 2015$ & $05 / 25 / 2016$ & $03 / 09 / 2016$ \\
Median last contribution date & & & \\
\hline of donors who gave to Sanders, after & $61.5 \%$ & $89.6 \%$ & $44.9 \%$ \\
Super Tuesday & $38.7 \%$ & $70.1 \%$ & $16.9 \%$ \\
Acela primaries (Super Tuesday III) & $15.7 \%$ & $33.3 \%$ & $4.6 \%$ \\
Clinton became presumptive nominee & $3.0 \%$ & $6.2 \%$ & $0.8 \%$ \\
Sanders endorsed Clinton & $0.1 \%$ & $0.0 \%$ & $0.0 \%$ \\
\hline End of Democratic convention & & & \\
\hline
\end{tabular}

October 1, 2015, and March 6, 2016 vs. March 9, 2016. If first donation dates are indication of interest/persuasion, this suggests that the hidden and immediately visible donors may be quite similar in their motivations for contributing, and perhaps that income or wealth is the primary difference between hidden and immediately visible donors. It is the repeat donors - who are also mostly early donors - who stand out, and they might be the donors who most affect the the campaign's policy positions.

Again, we are looking at the data from a single campaign. Depending on the nature of different campaigns, contextual factors, and primary election dynamics, the profile of the hidden donor population might vary across election cycles and candidates. If the hidden donors - who provided one-third of contribution dollars to Sanders in 2016 - can be further mobilized with certain issue positions, a campaign may choose to do just that. Hidden donors have, after all, the potential to give more and perhaps become visible. If they are more economically representative, the campaign may find it more beneficial to focus on small donors and retaining policy positions closer to the median voter. However, if the campaign's donor base cannot be mobilized this way, the campaign may choose to diverge from the median voter to attract more rich donors.

Are the three classes of donors actually any different in policy preferences? We cannot conclude that they are with only administrative data, and much less with just Sanders' 2016 
campaign. However, we believe it is worth further investigation. Uncovering hidden donors clearly shows that we need to better understand who the presidential campaign perceives to be major financial electorate, and whether catering improves a campaign's chances of primary and general election success.

\section{Conclusion}

How is our understanding of campaign finance restricted by the Federal Election Commission (FEC)'s data reporting process? Because only transactions that exceed cycle-to-date aggregate of $\$ 200$ are disclosed, many donors' contribution records are censored, either entirely or in part. We have shown that small donors, who are usually "hidden" due to censoring (hence the term hidden donors), are distinct from large donors. Unfortunately, it has been only large donors who were usually visible to campaign outsiders and researchers (visible donors). Hence we argue that our knowledge of individual campaign contributors has been incomplete.

Hidden donors to Sanders 2016 campaign far outnumbered visible donors, and for every visible donor to his campaign, there were seven who were hidden. Also, these hidden donors, relative to visible ones, were more likely to be students, females, and racial/ethnic minorities. This hints, consistent with the existing literature, that we usually only see a limited picture of much wealthier, privileged donors' political behavior when using censored campaign contributions data.

Hidden donors on average contribute later in the election than visible donors, and their giving generally occurred when the race was competitive. The median hidden donor started giving to Sanders a week before the primaries started, and did not give more than once or twice - whether it be a lack of enthusiasm, Sanders' diminished viability, or the donor's constricted campaign budget, is difficult to identify with our data. Whichever is the case, the hidden donors largely cleared out around March 2016, while a substantial portion of visible donors continued to give even with their candidate's dwindled prospects. This observation cannot be made with survey-based methods, with daily aggregation over all donations, or with campaign-level data aggregation.

The hidden donors, in aggregate, provided up one-third of the contributions to Sanders from individuals. While this proportion may be overestimated due to the uniquely popular, small-donor powered nature of the Sanders campaign, the hidden donors are still a significant subset of the financial constituents that a politician must be responsive to. If hidden donors are providing significant financial support to a campaign, it is likely that they have a more important influence on campaign platforms than previously acknowledged.

We also demonstrated the importance of donors who were hidden in the beginning but eventually became visible, who provided about half of Sanders' funds from individuals. These eventually visible donors were more likely to be early givers than the hidden donors - something that was not observed with traditional FEC data. For this class of donors, campaigns are likely to target solicit money from them until they have maxed out their contribution limits. 
Overall, looking into hidden donors' contributions and eventually visible donors' first contributions demonstrate the need to better understand how campaigns perceive and tailor their messages to all their contributors.

Fortunately for campaign finance scholars, the reliance on intermediary committees is ever increasing. Not only is the usage of ActBlue to solicit online donations now widely prevalent in Democratic campaigns, but the GOP is also trying to attract small donor by building a similar intermediary committee called WinRed, which will also be subject to the same strict set of disclosure regulations as ActBlue. While we may never be as lucky have such rich contributions data from a major presidential candidate, this ever-increasing reliance on intermediaries/conduits, and that the $\$ 200$ requirement stands unadjusted by inflation, will help us study small donors in the future. 


\section{References}

Associated Press. 2015. "Bernie Sanders pulls in nearly as much cash this quarter as Hillary Clinton." Chicago Tribune. October 1, 2015. http://www.chicagotribune.com/news/ nationworld/politics/ct-clinton-sanders-fundraising-20150930-story . html. (accessed November 19, 2018).

Barber, Michael. 2016. "Donation motivations: Testing theories of access and ideology." Political Research Quarterly 69(1):148-159.

Barber, Michael J, Brandice Canes-Wrone and Sharece Thrower. 2017. "Ideologically sophisticated donors: Which candidates do individual contributors finance?" American Journal of Political Science 61(2):271-288.

Blevins, Cameron and Lincoln Mullen. 2015. "Jane, John... Leslie? A Historical Method for Algorithmic Gender Prediction." DHQ: Digital Humanities Quarterly 9(3).

Bonica, Adam. 2011. "Small Donors and Polarization." Boston Review. July 22, 2011. http://bostonreview.net/bonica-small-donors-polarization. (accessed November 19, 2018).

Brown, Clifford W, Lynda W Powell and Clyde Wilcox. 1995. Serious money: Fundraising and contributing in presidential nomination campaigns. Cambridge University Press.

Bump, Philip. 2016. "Bernie Sanders keeps saying his average donation is $\$ 27$, but his own numbers contradict that." Washington Post. April 18, 2016. https://www.washingtonpost.com/news/the-fix/wp/2016/04/18/ bernie-sanders-keeps-saying-his-average-donation-is-27-but-it-really-isnt/ ?utm_term=.15cbffe56b6a. (accessed November 19, 2018).

Christenson, Dino P and Corwin D Smidt. 2011. "Riding the waves of money: contribution dynamics in the 2008 presidential nomination campaign." journal of Political Marketing 10(1-2):4-26.

Corasaniti, Nick. 2016. "Bernie Sanders Campaign Showed How to Turn Viral Moments Into Money." The New York Times. June 24, 2016. https://www.nytimes.com/2016/06/25/ us/politics/bernie-sanders-digital-strategy.html. (accessed November 19, 2018).

Culberson, Tyler, Michael P McDonald and Suzanne M Robbins. 2018. "Small Donors in Congressional Elections." American Politics Research p. $1532673 X 18763918$.

Dawood, Yasmin. 2015. "Campaign Finance and American Democracy." Annual Review of Political Science 18:329-348.

Ensley, Michael J. 2009. "Individual campaign contributions and candidate ideology." Public Choice 138(1-2):221-238.

Foran, Clare. 2016. "Bernie Sanders's Big Money." Washington Post. March 1, 2016. https : //www.theatlantic.com/politics/archive/2016/03/bernie-sanders-fundraising/ 471648/. (accessed November 19, 2018). 
Francia, Peter L, John C Green, Paul S Herrnson, Clyde Wilcox, Lynda W Powell et al. 2003. The financiers of congressional elections: Investors, ideologues, and intimates. Columbia University Press.

Gaudiano, Nicole. 2016. "Revolution Messaging helps drive Sanders' 'political revolution'." USA Today. March 18, $2016 . \quad$ https:// www . usatoday.com/story/news/politics/elections/2016/2016/03/18/ revolution-messaging-helps-drive-sanders-political-revolution/81977160/. (accessed November 19, 2018).

Graf, Joseph, Michael Malbin and Costas Panagopoulos. 2006. Small donors and online giving: A study of donors to the 2004 presidential campaigns. Institute for Politics, Democracy \& the Internet, Graduate School of Political Management, George Washington University.

Heerwig, Jennifer A. 2016. "Donations and dependence: Individual contributor strategies in house elections." Social science research 60:181-198.

Imai, Kosuke and Kabir Khanna. 2016. "Improving ecological inference by predicting individual ethnicity from voter registration records." Political Analysis 24(2):263-272.

Johnson, Bertram. 2010. "Individual contributions: A fundraising advantage for the ideologically extreme?" American Politics Research 38(5):890-908.

Johnson, Bertram N. 2013. Political giving: Making sense of individual campaign contributions. FirstForumPress, onc.

Karpf, David. 2013. The Internet and American political campaigns. In The Forum. Vol. 11 De Gruyter pp. 413-428.

Key, Valdimer Orlando. 1964. Politics, parties, and pressure groups. 5 ed. Crowell.

Khanna, Kabir, Kosuke Imai and Hubert Jin. 2017. wru: Who are You? Bayesian Prediction of Racial Category Using Surname and Geolocation. R package version 0.1-7. https://CRAN.R-project.org/package $=$ wru

Lee, Michelle Ye Hee. 2016. "Fact Checker: Sanders's claim that he 'does not have a super PAC'." Washington Post. February 11, 2016. https://www.washingtonpost.com/news/fact-checker/wp/2016/02/11/ sanderss-claim-that-he-does-not-have-a-super-pac/?utm_term $=.3 \mathrm{~b} 597 \mathrm{c} 7129 \mathrm{cc}$. (accessed November 19, 2018).

Magleby, David B, Jay Goodliffe and Joseph A Olsen. 2018. Who Donates in Campaigns?: The Importance of Message, Messenger, Medium, and Structure. Cambridge University Press.

Malbin, Michael J. 2009. "Small donors, large donors and the Internet: The case for public financing after Obama." Unpublished manuscript .

Malbin, Michael J. 2013. "Small donors: Incentives, economies of scale, and effects." The Forum 11:385-411. 
Mehta, Seema, Anthony Pesce, Maloy Moore and Christine Zhang. 2016. "Bernie Sanders's Big Money." Los Angeles Times. June 3, 2016. https://www.latimes.com/projects/ la-na-pol-sanders-donors/. (accessed November 19, 2018).

Mitchell, Joshua L, Karen Sebold, Andrew Dowdle, Scott Limbocker and Patrick A Stewart. 2015. The political geography of campaign finance: Fundraising and contribution patterns in presidential elections, 2004-2012. Springer.

Mullen, Lincoln. 2018. gender: Predict Gender from Names Using Historical Data. R package version 0.5.2. https://github.com/ropensci/gender

Panagopoulos, Costas and Daniel Bergan. 2006. "Contributions and contributors in the 2004 presidential election cycle." Presidential Studies Quarterly 36(2):155-171.

Panagopoulos, Costas and Daniel Bergan. 2007. "Online fund-raising and contributors in the 2004 presidential campaign." Social Science Computer Review 25(4):484-493.

Patten, Eileen. 2016. "The Nation's Latino Population Is Defined by Its Youth." Pew Research Center. April 20, 2016. http://www.pewhispanic.org/2016/04/20/ the-nations-latino-population-is-defined-by-its-youth/. (accessed November 19, 2018).

Qiu, Linda. 2015. "Is Bernie Sanders the only presidential candidate without a super PAC?" Politifact. September 30, 2015. http:// www . politifact.com/truth-o-meter/statements/2015/sep/30/bernie-s/ bernie-sanders-only-presidential-candidates-withou/. (accessed November 19, 2018).

Rhodes, Jesse H, Brian F Schaffner and Raymond J La Raja. 2018. "Detecting and Understanding Donor Strategies in Midterm Elections." Political Research Quarterly p. 1065912917749323.

Smidt, Corwin and Dino Christenson. 2012. "More Bang for the Buck: Campaign Spending and Fundraising Success." American Politics Research 40(6):949-975.

Verba, Sidney, Kay Lehman Schlozman and Henry E Brady. 1995. Voice and equality: Civic voluntarism in American politics. Harvard University Press.

Wilcox, Clyde. 2008. Internet fundraising in 2008: A new model? In The Forum. Vol. 6 De Gruyter. 